\title{
Digitalization of Bangladesh Judiciary and Access to Justice
}

\author{
Mohammad Ikbal Hasan ${ }^{1}$ and Fahmida Johura Rupa ${ }^{2}$ \\ ${ }^{1 \& 2}$ Department of Law, University of Information Technology and Sciences (UITS), Dhaka, Bangladesh. \\ *Correspondence: ikbalhbd@gmail.com (Mohammad Ikbal Hasan, Assistant Professor, Department of Law, UITS, Dhaka, \\ Bangladesh).
}

\begin{abstract}
The vision of 'Digital Bangladesh' as articulated by the present government of Bangladesh is inseparably related to establishing delivery of justice to the citizens through maximum use of technology. Judiciary, being the one of three main organs of the government, is the key governance and rule of law institution. Independence of Judiciary is ensured in the Constitution of Bangladesh to ensure access to justice for all. Information and communication technologies (ICTs) are today considered to be an indispensable tool for both case management and efficient delivery of judicial services. Much like other developing and transitional countries, the judicial system in Bangladesh faces the same constraints and bottlenecks. More than 3 million pending cases have created a high backlog in the judiciary. Consequently, the cases take an inordinately long time to reach their logical end and litigation costs keep on mounting. The vulnerable and marginalized sections of society suffer the most. Perhaps the biggest challenge for the judiciary in the country is to reduce the delay in the court process and remove the backlog of cases. The pragmatic step to E-judiciary is inevitable to integrate the existing efforts and to digitalize the judiciary of Bangladesh aiming at reducing citizens' time, cost, and hassle to access judicial services and to make the system more efficient and transparent. E-judiciary, a whole tech-based judicial system, may bring a radical change in the field of the administration of justice. This paper identifies the nexus between access to justice and digitalization, analyzes the current pattern of administration of justice and upholds the loopholes of the traditional justice delivery system and core necessity of E-judiciary. Finally, it concludes with challenges and a way out for a digitalized judiciary to accelerate access to justice for mass people.
\end{abstract}

Keywords: Administration of Justice, Digitalization, Backlog, Judiciary, E-court, Records, and Court process.

\section{INTRODUCTION:}

Use of Information and Communication Technology (ICT) is considered one of the key elements to improve justice administration. The direct correlation between rule of law, social and the economic development and access to justice has further encouraged greater use of ICT in justice systems in developing countries. It can also contribute in delivery of justice in timely fashion. The e-justice system means an important step towards achieving excellence in providing court related services for the masses, especially vulnerable groups in Bangladesh. The present government of Bangladesh has promised through its election manifesto to make the country digitalized and with the end of making a 'Digital Bangladesh', it is going ahead with the mission termed as "Vision 2021".

The formal justice system in Bangladesh remains relatively inaccessible for the vast majority of people. A large case backlog is slowly overwhelming the court administration and undermining access to justice. It is 
increasingly acknowledged that this situation is a barrier to good governance and the rule of law and those steps must be taken to address the problems (Karim, 2010). A well-functioning judiciary is a crucial determinant of a country's economic performance. It is widely understood that a judiciary effective in enforcing the rule of law would not only be conducive to trade, financing and investment but would also promote social peace and trust. 'Digital Bangladesh' aims to ensure social justice through maximum use of technology. As a Constitutional organ, without invoking technology in our judicial system, 'Digital Bangladesh' will not be completed. But the real scenario is awfully worse; the court buildings, record rooms and other mechanisms have no minimum touch of digitalization which has created an unbearable logjam of cases.

This paper focuses on various aspects of implementing e-judiciary in Bangladesh. It attempts to investigate how the computerization in judiciary has become an effective tool to bring down the pendency of cases and to reduce the delay. The prospects and problems in process of digitalization of judiciary in Bangladesh are identified emphasizing on the specific recommendations for access to justice through digitalization.

\section{METHODOLGY:}

Qualitative survey method has been used in this study. Secondary sources i.e.; relevant reports, project design documents and court documents have been reviewed to collect data. Key Informant Interviews (KIIs) were conducted among Registrar General, Senior Assistant Registrar, and Special Officer for IT in Supreme Court of Bangladesh, Judges, Lawyers and Litigants. Literature review of relevant journals, articles and papers from home and abroad was employed to analyze the findings and draw policy recommendations.

\section{Judiciary of Bangladesh}

Bangladesh is a unitary democratic Republic having a population of around 164 million (Khan, 2013). The judiciary comprises of the Supreme Court at the higher level followed by a hierarchy of civil and criminal courts at the district level. In the Supreme Court there are two divisions namely- the High Court Division and the Appellate Division, of which the Appellate Division is functionally the highest Court of the Republic. The Constitution of the Republic has guaranteed the functional independence and freedom of the judges in deciding any civil or criminal disputes or the matters relating to the constitutionality. Under the Constitution, being an organ of the State the judiciary has to perform its responsibility of administering justice without any fear or favor (Sinha, 2015).

i) Higher Judiciary - Appellate Division and High Court Division basically entertain the Appellate Jurisdiction except some cases are originally heard by the latter. A suit in HCD, any appeal to HCD or Appellate Divisions, Review, Revision, writ etc. can be filed by submitting petition manually with a mandatory physical presence which is very sluggish, time-consuming and risky for the party.

ii) Lower Judiciary - Lower judiciary has two sides i.e. criminal courts and civil courts and both act as the court of first instant except some appeals are heard by Sessions Judge, District Judge or by other lower grade Judges. A case in criminal matter may be filed either in session or magistrate court or in police station whereas a civil case must be filed in civil court. In both cases, suits are filed through instituting FIR, complaint or plaint (Section 154, 1898) which com- pulsorily requires physical presence of human beings.

In hearing and trial stages, examination or crossexamination of witness, taking evidence is followed by 200 years old British-made methods. It is noteworthy that the Evidence Act, 1872, the fundamental prevailing law of evidence, doesn't admit digital evidences (Alam et al., 2020).

\section{Digitalization of Judiciary}

The interface between law and technology is a growing sphere. The law must assume new dimensions to suit the needs of an IT-based modern society and it should play a dynamic role like a living organ. Already, the impact of ICT on court systems can be felt with case management systems, court administration, human resources, online libraries and many other ICT-enabled facilities that are now available with stakeholders.

In Bangladesh, the digitalization of courts, primarily with an aim to remove the backlog of cases, make the justice process swift and keep abreast with the fast-moving world, started in 2009. Not only that the 
digitalization of court is 'environmentally friendly', but also it ensures quick disposal of existing cases. Digitalization of court is a broad term and may be understood as referring to digitalization of both records and court process. As part of the digitalization process, the court documents-if hand-written or computer composed-have to be scanned and produced in a portal, which should be password secured in case of private and confidential information.

Currently getting judicial service is a time consuming process, particularly accessing to legal information. If we can provide the people with the right information of law and explanation of law using technology at the doorsteps then it is possible to reduce case filings. Digital records are normally free of charge and accessible without restriction. A proper regul- ation of digitalized court system would ensure that only appropriate authorities are capable of making necessary changes, such as amending or uploading court orders, in the portal with a view to preventing online fraud (Prakash, 2014). It will bring massive turnaround practice in legal battle which is heavily reliant on paper based model. It will take time before the entire court system becomes digital. Once it is digitalized it will bring great relief to the litigants at one click. The judiciaries in most countries however face similar problems. Cost, delay and complexity in the court system were identified in the UK as the major problems with civil justice process in 1997, which eventually resulted in the subsequent reforms and the overture of the Civil Procedure Rules (CPR), 1997. The digital system therefore has to be taken as effective on the parties to whom the orders are addressed, such as the prison authority who should be able to release a prisoner based on the order found online in the appropriate portal. The concept of e-courts could be thought of in two environments such as the court with brick and mortar concept, which is the courts in reality, and virtual courts. The first e-court as a paperless court is not a virtual court but a real court; where in the use of paper is dispensed with. Virtual courts will have no court hall, no timing of a specific nature, but will have an environment of lawyers, judges, parties and witnesses having meeting and exchange of documents by utilizing the facility of video conference, exchange of documents through Electronic Documents interchange, use of digital signatures. The technological improvements like Skype, face time, while could be used to have one to UniversePG I www.universepg.com one look among different stakeholders simultaneously and also otherwise, to have discussions dialogues, the exchange of documents could be done by discoveries, interrogatories, and admissions which are available in the existing laws.

The system of e-courts in Singapore is an innovative combination consisting of a multitude of concepts, services and technologies such as the e-Chambers, the Electronic Filing System, Technology Courts, Law Net and Justice Online. Imagine a courtroom, which we could walk into, not with sheaves of papers, affidavits, bundles of documents and volumes of authorities, but with an electronic notebook. Plugging the notebook into an appropriate socket in the courtroom-in a flash- the judge and lawyers would immediately be able to follow arguments, evidence and authorities-at the click of a mouse (Shahani and Jain, 2019). The use of technology in the Singapore courts has made a key contribution towards building up an institution in the administration of justice which is widely acknowledged as world-class and a first amongst equals. The judiciary of Bangladesh also needs to move towards a paperless courtroom, and the birth of the cyber-court. It is hoped that we will be able to appreciate that technology is but a means in fulfilling the age-old duty of delivering justice to the people (Oskamp et al., 2014).

\section{Access to Justice}

The Constitution of the People's Republic of Bangladesh guarantees to all citizens of Bangladesh equality before law and the equal protection of law. It reiterates that it is the inalienable right of every citizen to enjoy the protection of the law, to be treated in accordance with law, and only in accordance with law. The State is duty bound to provide timely justice to all its citizens. One important constraint recognized and acknowledged by many stakeholders is the lack of speedy and efficacious disposals of cases (Golub and Huda, 2015). While the police and Village Courts are close to where people live, District Courts are much less accessible in terms of distance, particularly for those in small towns and rural areas, Costs and corruption in all parts of the system and interference by the political and more powerful members of society make it difficult for the poor and vulnerable groups to access justice (Moran, 2016; Hasan, 2021). The lack of access of a vast number of people to the formal justice system is one of most serious challen- ges faced by any 
government. The massive backlog of cases endemic within the judicial system denies the right of the people to effective protection of law and the right to have access not only to the remedies they are legally entitled to but in many cases access to the courts itself. The end result is that people's trust in the formal system is being eroded and they are either suffering without remedy or are submitting to pro- cesses which are extra-judicial and at times inherently illegal. The axiom "justice delayed, justice denied" is no longer an exception for certain litigants - it has become the rule. Thus, "one of the key constraints faced by the judiciary is the large case backlog, which is placing considerable pressure on the court system and is limiting attempts to broaden access to justice. It is also symptomatic of a number of other issues, including complex procedures and a lack of consistent case management mechanisms" (UNDP, 2010). Be- cause of corruption, mismanagement and irregular- ities in different levels of the judiciary, it has become difficult to deliberate justice in many cases (Masum, 2015). Perhaps the biggest challenge for the judiciary in the country is to reduce the delay in the court process and remove the backlog of cases. The judiciaries in most countries however face similar problems.

Table 1: Pending Cases in Higher and Lower Judiciary (During 1st July- $30^{\text {th }}$ September 2019)

\begin{tabular}{|c|c|c|c|c|}
\hline & $\begin{array}{c}\text { Civil } \\
\text { Cases }\end{array}$ & $\begin{array}{c}\text { Criminal } \\
\text { Cases }\end{array}$ & Others & Total \\
\hline $\begin{array}{c}\text { Supreme } \\
\text { Court of } \\
\text { Bangladesh } \\
\text { (Appellate } \\
\text { Division) }\end{array}$ & 14,992 & 7,427 & 177 & 22,596 \\
\hline $\begin{array}{c}\text { Supreme } \\
\text { Court of } \\
\text { Bangladesh } \\
\text { (High Court } \\
\text { Division) }\end{array}$ & 97,134 & $2,96,837$ & 96,829 & $4,90,800$ \\
\hline $\begin{array}{c}\text { All } \\
\text { Subordnate } \\
\text { Courts }\end{array}$ & $13,40,981$ & $17,86,262$ & & $31,27,243$ \\
\hline Total & $14,53,107$ & $20,90,526$ & 97,006 & $36,40,639$ \\
\hline
\end{tabular}

Source: Office of Registrar, Supreme Court of Bangladesh

Table 1 and 2 showed that 3.64 million cases are pending now. Civil cases comprised around 1.4 million of these cases where criminal cases are around 2 million. The scenario of only last three months refers that the number of cases filed is about 4.85 million; number of cases disposed is 4.43 million.
Table 2: Statistics of cases initiated, disposed of and under trial in Higher and Lower Judiciary (During 1st July- $30^{\text {th }}$ September 2019)

\begin{tabular}{|c|c|c|c|c|c|}
\hline & $\begin{array}{c}\text { Initiat } \\
\text { ion }\end{array}$ & Filed & Total & $\begin{array}{c}\text { Dispos } \\
\text { ed of }\end{array}$ & $\begin{array}{c}\text { Pend } \\
\text { ing }\end{array}$ \\
\hline $\begin{array}{c}\text { Supreme } \\
\text { Court of } \\
\text { Bangladesh } \\
\text { (Appellate } \\
\text { Division) }\end{array}$ & $\begin{array}{l}\stackrel{N}{ \pm} \\
\stackrel{ \pm}{0}\end{array}$ & $\stackrel{N}{N}$ & $\begin{array}{l}\tilde{\omega} \\
\stackrel{N}{0} \\
\stackrel{\infty}{ }\end{array}$ & Б & $\begin{array}{l}\text { N } \\
\text { un } \\
\text { Oొ }\end{array}$ \\
\hline $\begin{array}{c}\text { Supreme } \\
\text { Court of } \\
\text { Bangladesh } \\
\text { (High Court } \\
\text { Division) }\end{array}$ & $\begin{array}{l}+ \\
\infty \\
\infty \\
\ddot{N} \\
\stackrel{N}{ }\end{array}$ & $\begin{array}{l}\stackrel{N}{+} \\
\stackrel{\infty}{\infty}\end{array}$ & 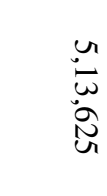 & $\begin{array}{l}N \\
N \\
\infty \\
N \\
U\end{array}$ & 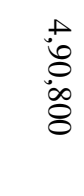 \\
\hline $\begin{array}{c}\text { All } \\
\text { Subordinate } \\
\text { Courts }\end{array}$ & $\begin{array}{l}\omega \\
0 \\
\infty \\
\infty \\
0 \\
0 \\
0\end{array}$ &  & $\begin{array}{l}\omega \\
u \\
0 \\
0 \\
0 \\
0 \\
0\end{array}$ & \begin{tabular}{l} 
\pm \\
\multirow{0}{*}{} \\
un \\
\pm
\end{tabular} & $\begin{array}{l}\omega \\
\text { Nu } \\
\text { Nu } \\
\text { N } \\
\text { W }\end{array}$ \\
\hline Total & 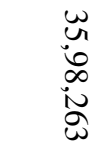 & $\begin{array}{l}+ \\
\infty \\
\infty \\
\infty \\
\infty \\
0\end{array}$ & $\begin{array}{l}t \\
0 \\
\infty \\
+ \\
= \\
\omega\end{array}$ & 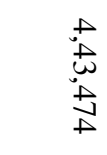 & 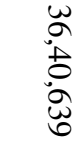 \\
\hline
\end{tabular}

Source: Office of Registrar, Supreme Court of Bangladesh

\section{Loop holes of traditional justice delivery system}

There are some specific constraints to access to justice including prohibitive costs, backdated pro- cedural laws, corruption and undue influence and lack of awareness of legal rights (Arifuzzaman et al., 2021). Long delay in court processes is caused by a variety of factors including a lack of management capacity both at the district and national level, lack of coordination between justice sector actors, lack of trained staff and shortages of judges, lack of trained and competent lawyers etc. Backlog of cases is the biggest impediment in the judiciary of Bangladesh. Currently there are more than 3.6 million cases pending in the Supreme Court and lower courts of the country. The huge backlog of cases is slowly overwhelming the justice delivery system, causing further delay in the disposal of cases and undermining people's access to justice. As with many countries in the developing world, Bangladesh's formal justice system is often perceived and reported to be inaccessible to some extent to the public with vulnerable groups (such as women, children, ethnic and religious minorities, the poor, and people with disabilities) facing particular difficulty in accessing timely and affordable justice. Lack of coordination and cooperation between justice sector agencies (such as the police, prisons and courts) slows down pro- ceedings and leads to prison 
overcrowding and large case backlogs that are slowly overwhelming the court administration and affecting access to justice. If a filing is done, notices are served in paper form to the parties. It is frequent that notices are concealed, counterfeited and delayed to be served to the intended party. In hearing and trial stages, whole court processes are completed in long-observed traditional methods. At the last stage of the trial, judges write down their judgments manually and pronounce the judgments.

The following problems are identified in present justice delivery-

- Inordinate delay involving service of process.

- Too many adjournments are being indulgently granted.

- Audio and video evidence is not currently legally acceptable as evidence.

- Too much time is elapsing between individual hearings, or between the filing and disposition of both civil and criminal cases.

- Judges are not "captains" of their courtrooms. Power and authority has been usurped by the bar/litigants.

- Witnesses are neither effectively managed nor efficiently coordinated.

- Significant monetary sanctions to compel recalcitrant advocates, litigants, witnesses or expert witnesses' compliance with codes, rules, policies, processes and procedures are not imposed.

\section{Nexus between access to justice and digitalization of judiciary}

As per the Constitutional provisions, Bangladesh is composed of three independent organs of the government. Independence of Judiciary is ensured in the Constitution of Bangladesh and further pronounced by the Apex Court in the landmark case Secretary, Ministry of Finance vs. Madder Hossain \& others case (52 DLR AD 82). As a Constitutional organ, we cannot think of a 'Digital Bangladesh' without a digital judiciary. However, the reality is extremely frustrating that the court buildings, record rooms and other mechanism have no minimum touch of digi- talization which has created an unbearable logjam of cases. Civil suits have turned into another name of 'injustice'. Judicial systems of Bangladesh, like other developing countries, continue to suffer from ineffi- ciencies that have a negative impact on socio- economic well-being. Commonly faced lacunae in judicial performance include (a) length of time it takes for cases to be disposed; (b) uncertainty in the progress of judicial proceedings; and (c) difficulty for the common man to access judicial services, parti- cularly related to the cases she/he is concerned with or is a party to. In this backdrop case flow management as an approach to keep track of cases and ensure their smooth passage through allocation of most appropriate time and resources forms the very backbone of the judicial system. Cash flow management techniques are now widely adopted as a way to reduce case backlog, render timely justice and increase predictability in the judicial system. Information and communication technologies (ICTs) are today considered to be an indispensable tool for both case management and efficient delivery of judicial services. While ICTs make it possible to address the information-intensive requirements of case management through its search and discovery capabilities, latest advances in technology (including those related to mobile devices) also ensure that information is provided to the citizens on a device of their choice and at a place of their choosing (Supra note 11).

The existing system of slow, interrupting and expensive justice delivery can't give remedy of peoples' grievance. Rural marginalized people suffer in every stage by middlemen, court officials or even by lawyers. Thus they become frightened to ask remedy. Illegal transaction, corruption, bribery, lack of accounttability can never be stamped out due to the deficiency of digitalization. In absence of online database in land offices, many ill-mined people make counterfeit deeds and documents which lead the weaker party to a disadvantageous position. The number of pending cases in all courts stood at 36, 40,639. This huge pile of cases is causing serious bar to seek justice by destructing time, money, hope and emotion of the parties. Though the case disposal rate is tentatively high, but this large number of cases can't be disposed in a shorter period without digitalization.

Case management system, an internal function of the court, if digitalized it'll enhance the efficiency, swiftness and flawlessness of the courts and court record room. It will reduce the possibility of losing, damaging or twisting any documents rather give a perpetual existence of the documents. Filing of cases and submitting e-documents will reduce the pile of 
papers in lawyer's chambers and court offices. This will consequently increase efficiency and reduce delay and complexity. Witness depositions may be recorded and in cases of urgency video recording of witness testimony may be admitted. This will fill the time gap of witness summoning, rendering the disposal of cases quicker. In addition, the case filing and management process, if found online through a digitalized system, will become more transparent and automatic, thereby reducing the possibility of individual adverse influences on a particular case. The crying of evil legacy can only be solved by rapid digitalization.

\section{Initiatives of Digitalization}

Several solutions have been developed towards digitalization of Bangladesh Judiciary. Courts are following by digitizing their Court records on administrative and judicial sides for converting them into e-records for facilitating following e-services through the web-portals using smart devices such as-

- Case Management Software in both Supreme Court and 3 pilot district courts;

- Online and SMS based Cause list and case information access for litigants in higher judiciary, which widens the platform for accessing the justice system with little effort and cost;

- Bail Confirmation through IT section of Supreme Court;

- Provision of Summons via Email has been inserted in procedural law;

- Developed web based Judicial Officers' Database Management Application to enhance transparency in the court administration process;

- Current position of the Cases being taken up in the Courts and updating of their changed status on the basis of orders and judgments passed by the Courts.

- Electronic filing of general diary in police station;

- The tracking system on the status and progress of cases in the lower courts by the upper judiciary and monitoring for supervising the reduction of case backlogs;

- All laws are available online (www.bdlaws.gov. bd);

- Monitoring dashboard in some courts to monitor the performance of individual courts.
Though Bangladesh judiciary has not been completely digitalized, yet Supreme Court has started to upload the latest landmark judgments, cause list in their website. Bangladesh Police has launched online GD filing system recently. 20 lower courts of Sylhet have been oriented with digital technologies. The adoption of ICT in Judiciary has been disappointing as compared to the other pillars of the state, namely the Executive and the Legislative.

In Bangladesh, the total number of Internet Subscribers has reached 99.569 Million and the total number of Mobile Phone subscribers has reached 164.170 Million at the end of October, 2019 (BTRC, 2019) out of around 170 million populations. This is a milestone for citizens to get e-service of judiciary.

\section{Challenges of E-Judiciary}

There are various challenges in implementing digital judiciary-

- The e-judicial setup demands high level of fund infusion into the programme;

- One of the biggest challenges is the complete digitization of its records and proceedings;

- It will be difficult at the outset to make everyone familiar with the digitalized court system, for the concept is relatively new and requires technical knowledge;

- Quality infrastructure also plays an integral role in its success. Infrastructural bottlenecks like power shortages, low bandwidth, etc. hamper sustained e-justice;

- The new media and internet open up the user to a world of information and knowledge, but unfor- tunately, very little is in the native language and much of the content is not locally relevant;

- Introduction of web based project management will only succeed when it is not bogged down by infrastructural bottlenecks like low bandwidth, poor connectivity or even no electricity;

- The cost of internet connectivity is still one of the highest in the region and is well below the affordability of the common citizen. Broadband access is still in its infancy;

- The still lacking institutional capacity that would be required to implement Digital Bangladesh;

- Change in mindset \& willingness to use technology; 
- This uninterrupted internet connection throughout the courts and appropriate training for the judges and staffs for the new system;

- A change in the mindset of the judiciary from a paper-pushing culture to a paperless culture.

However, what is more difficult than the concept of digitalization is its implementation. It will overturn hundreds of years practice in legal arena which is heavily reliant on paper based model.

\section{Way Forward}

Digitalization of judiciary is inevitable to ensure speedy disposal of cases and help to improve public confidence over judiciary through bridging the technology in the judicial process. The following recommendations are identified to make it reality:

- The judicial system should be made truly independent;

- A computerized case documentation and management system should be introduced in order to provide access to information for citizens seeking to use the formal justice system; this would include all relevant information, such as a general diary, First Information Reports, and details on the current status of individual cases;

- Laws should be changed to make it adaptable to e-judiciary; -Modern communications systems, such as mobile phones and SMS, should be used to inform citizens of summons;

- The whole old-fashioned courtrooms should be accommodated with new technologies;

- Court record room should be modified with Online Database System (ODS) and case Management System (CMS) as well.

- Adequate budget should be allocated;

- Judges, lawyers, law enforcing agencies and court officials should be trained so that they can cope with e-judiciary;

- Use of technology has high risk of being hacked, distorted and misused. Proper steps should be taken to tackle such risks;

- As Bangladesh has lack of essential technologies, advance technologies, services, experts should be exported;

- Required laws, especially the Evidence Act, 1872 should be amended making parallel with ejudicial system;

- Backup plan should be ready for the urgencies;
- National and sub-national committee must be formed to control and utilize the whole scheme and to hear the grievance of the people;

- People must be aware and cooperative to use the e-judiciary and Modern witness depo- sition mechanism in courts;

- Internet connectivity and Wi-Fi Access in 64 district courts;

- Scale-up online cause list in 64 districts;

- Establishing e-Court for both higher and subordinate courts;

- Record room automation: Record digitization and archiving;

- Establishing video conferencing facility in all districts and Central Jails;

- Introduce a Management Information System of the judiciary of Bangladesh;

- Capacity development of judicial officers.

\section{Outline of e-judiciary}

It is neither possible nor desirable to digitalize the whole judicial system overnight. The digitalization of judiciary can at best be divided into two parts: structural digitalization and systematic digitalization.

\section{i) Structural Digitalization}

Our congested court rooms are not largely up-to-date. Most of the court room has no internet access, video conferencing management, e-cause list, online submission system, modern database etc. which causes delay, mismanagement, corruption, loss of unnecessary expenses in the cases. A digital court room must have uninterrupted internet connection. Video conferencing may help to hear and try the criminals or defendants, complainants or plaintiffs and witnesses from jail custody or distant area. Adequate computers for each courtroom should be set which will help threefold mechanism i.e. judges, attorneys and litigants as well as the court officers. Multimedia projector, camera, monitor, electronic recorder, VCR/DVD player, printer etc. are needed to simplify and quicken the court activities and make proper use of working hours of the court.

Data analyzer may be inserted so that it would help to analyze thousands of data within a second. Using different cameras, especially the evidence camera can instantly convert a paper document or physical exhibit to an e-image. 


\section{ii) Systematic Digitalization}

(a) E-case filing - For filing a case, it is immaterial of human presence which causes unnecessary sufferings to the people. In e-case filing system, a person may create a personal account with secured password where every updates of the case can be provided within a moment. Thus, this service can reached up to peoples' bedroom.

Different countries like USA, UK, and Singapore etc. have already started to use e-filing. Bangladesh has reached 99.569 Million Internet Subscribers at the end of October, 2019 which opened the door of digitalization easily.

(b) Digital Case Management System (DCMS) Case management system, an internal function of the court, if digitalized, it will enhance the efficiency, swiftness and flawlessness of the courts. Case management software helps to better use, manage, consolidate, share and protect the confidential data of the court record room. It will reduce the possibility of losing, damaging or twisting any documents rather give a perpetual existence of the documents.

c) Use of Mobile SMS Service - $n$ Bangladesh the total number of Mobile Phone subscribers has reached 164.170 Million at the end of October, 2019 out of around 17 million populations. Cause list of particular cases may be sent via SMS to the common people.

Any latest update, query or information may reach within a short period of time by SMS. So, this system may help secure justice. Finally, a master-plan is needed to check the high risk of technology and people must be aware and cooperative to use the e-judiciary (Hussain, 2015).

\section{CONCLUSION:}

An effective and efficient system of E-courts would require a radical paradigm change in the existing structure. Thus, there is need to bring about a change in the attitudes and a change in the mindset, the way we have been conditioned to conduct our affairs, to keep up with the fast moving world. Mandatory changes in legal provisions to give effect to the technology objectives are much needed. Lawyers are required to shift to a new 'paperless' model. It would certainly take time to get adept with the use of electronic documents instead of 'paper', but this change should be treated as inevitable issues of access to justice. More- over, adequate training for lawyers, software costs and all the stated anxieties are concerns which face us with brooding omnipresence. We must always remember that justice must be assisted, not dominated, by technology. Technology alone does not improve the system. It is people, assisted by technology, who make the Justice System work. E-Governance is the key word in every department of life today. It in- creases productivity, enhances transparency and accountability, reduces red tape and corruption in administration. E-judiciary, a whole tech-based judicial system, may bring a radical change in the field of the administration of justice. Moving toward a 'Digital Bangladesh', skipping judiciary from digitalization will be an incomplete journey to the digitalization. It is high time the government of Bangladesh took initiatives for an e-judiciary standing two years from reaching the 'Vision-2021'. It is indeed a matter of great success that the digitalization of courts in Bangladesh has already started, while many western countries are still in the process of transformation to the digital model. It will take time before the entire court system becomes digital. Until then, the lawyers, litigants and judges should adapt to the new system and provide constructive feedback for the better management and development of the digital model. Those days are not far for the judiciary of Bangladesh when it should all start with a mere click of the mouse. As Bangladesh proceeds boldly to implement it's ambitious and yet achievable Digital Bangladesh priorities, it faces several challenges. Although Bangladesh has its own limitations in resources, capacity and knowledge, the country is staring at a tremendous opportunity to leapfrog (Islam et al., 2012).

However, various pragmatic plan and projects have been taken to the progress of E-Judiciary (Rajon and Zaman, 2008). Many departments of government across the country are working hard at it and in time to come the dream of Digital Bangladesh along with E-judiciary are sure to become a reality.

\section{ACKNOWLEDGEMANT:}

I acknowledge the effort of the co-author for the cordial support in data collection and completion of this research and special gratitude to office of Registrar, Supreme Court of Bangladesh for the cooperation during data collection of this paper. 


\section{CONFLICTS OF INTEREST:}

The researcher declares no potential conflict of interest concerning the paper, data collection and publication of the same.

\section{REFERENCES:}

1) Alam S, Al-Amin M, and Mukta SY. (2020). Sketch of the copyright act, 2000 in Bangladesh: enforcement, impediments and solutions, Asian J. Soc. Sci. Leg. Stud., 2(6), 129-137.

https://doi.org/10.34104/ajssls.020.01290137

2) Arifuzzaman M, Rafee FER, and Islam MJ. (2021). Exploration of poverty and human rights violation: a legal analysis, Asian J. Soc. Sci. Leg. Stud., 3(1), 10-22. https://doi.org/10.34104/ajssls.021.010022

3) Bangladesh Telecommunication Regulatory Commission (BTRC), (2019), the available online at -

http://www.btrc.gov.bd/content/mobile-phone-s ubscribers-bangladesh-october-2019

4) Golub, Stephen and Shahnaz Huda, (2015). Evaluation of the Bangladesh Judicial Strengthening Project (JUST), Supreme Court of Bangladesh.

https://erc.undp.org/evaluation/documents/dow $\underline{\text { nload/9296 }}$

5) Hasan N. (2021). Political modernization in the developing countries: challenges and prospects, Asian J. Soc. Sci. Leg. Stud., 3(3), 41-48.

https://doi.org/10.34104/ajssls.021.041048

6) Hussain, Rasel. (2015). The Emerging Digital Culture of Bangladesh: Problems and Prospects, Journal of Philosophy, Culture and Religion, ISSN 2422-8443.

7) Islam, Md. Zohurul and Rizwan Khair. (2012 June). Preparation of E-Government in Bangladesh: An Exploratory Analysis. JU Journal of Information Technology (JIT), 1(2): 19-25.

8) Karim, Md. Abdul, (2010). Digital Bangladesh for Good governance, Bangladesh Development Forum 2010, Bangabandhu International Conference Centre, 2.

https://erd.portal.gov.bd/sites/default/files/files/ erd.portal.gov.bd/page/60daef34_a889_4a94_a
902_f3a4a106762b/BDF2010_Session\%20VI $\% 20(1) . p d f$

9) Khan, Mohammad Shakwat Hossain, (2013), Summary Report on Court Services Situation Analysis, Judicial Strengthening Project (JUST) Supreme Court of Bangladesh, UNDP Bangladesh, 11-15.

http://www.undp.org/content/dam/bangladesh/d ocs/Projects/JUST/Summary Report_on $\% 20 \mathrm{C}$ ourt\%20Services\%20Situation\%20Analysis.pd $\underline{\mathrm{f}}$

10) Masum, Md. Reazul Al. (2015). Transforming towards digitalization of Bangladesh Judiciary. Judicial Strengthening Project (JUST), UNDP Bangladesh.

http://www.bd.undp.org/content/bangladesh/en/ home/ourperspective/ourperspectivearticles/20 15/07/09/transforming-towards-digitalization-of -bangladesh-judiciary.html

11) Moran, Greg, (2016). Access to Justice in Bangladesh Situation Analysis, Summary Report 2015. Justice Sector Facility Project, Ministry of Law, Justice and Parliamentary Affairs, Government of the People's Republic of Bangladesh funded by UKaid and UNDP. https://www.undp.org/content/dam/bangladesh/ docs/Publications/Pub2016/Access2015.pdf

12) Oskamp, Anja, Arno R. Ladder \& Martin Apostolic, (2004). IT support of the judiciary in Australia, Singapore, Venezuela, and three European countries, Computer/Law Institute, Virile Universities Amsterdam.

https://www.springer.com/gp/book/9789067041 $\underline{683}$

13) Prakash, Setlur B. N. (2014). E-Judiciary: a Step towards Modernization in Indian Legal System, J. of Education \& Social Policy. http://jespnet.com/journals/Vol_1_No_1_June 2014/15.pdf

14) Rajon, S. A. A. and S. A. Zaman. (2008). Implementation of e-governance: Only way to build a corruption-free Bangladesh. 11th International Conference on Computer and Information Technology, Khulna, Bangladesh, 430-435.

https://ieeexplore.ieee.org/document/4802970

15) Section 154, the Code of Criminal Procedure, 1898 and Section 26, the Code of Civil Procedure, 1908. 
16) Shahani, J., and P. Jain, (2019). e-Courts: Infusion of Information Technology into the Justice Delivery System.

https://judicial.assam.gov.in/portlets/e-court-inf usion-of-it-in-the-justice

17) Sinha, Surendra Kumar, (2015). Contribution of the Judiciary of Bangladesh in Strengthening Rule of Law and Democracy, public lecture delivered at Gujarat National Law University, Gujarat, India.

http://ww3.supremecourt.gov.bd/resources/cont ents/Speech by HCJ SK Sinha GNLU.pdf
18) 52 DLR AD 82.

19) Supra note 11.

20) UNDP, (2010). Project Factsheet-Judicial Strengthening Project. Supreme Court of Bangladesh and UNDP.

http://www.bd.undp.org/content/dam/banglades h/docs/Projects/JUST/Final\%20JUST\%20Prod oc.pdf

Citation: Hasan MI, and Rupa FJ. (2021). Digitalization of Bangladesh judiciary and access to justice, Asian J. Soc. Sci. Leg. Stud., 3(3), 49-58. https://doi.org/10.34104/ajssls.021.049058 @) (i) 